\title{
0 valor do atleta com deficiência. Estudo centrado na análise de um periódico português
}

\author{
Ana L. Pereira ${ }^{1}$ \\ M. Adília Silva ${ }^{1}$ \\ Olga Pereira ${ }^{2}$
}

https://doi.org/10.5628/rpcd.06.01.65

\author{
${ }^{1}$ Universidade do Porto \\ Faculdade de Desporto \\ Portugal \\ ${ }^{2}$ Colégio Didálvi Cooperativa de Ensino \\ Barcelos \\ Portugal
}

\section{RESUMO}

A prática de desporto por pessoas com deficiência tem vindo a desenvolver-se significativamente. Prova disso são os Jogos Paralímpicos, que representam o símbolo máximo do desporto para estas pessoas. Contudo, apesar desta evolução, estas competições parecem não ter uma cobertura relevante por parte dos mass media, parecendo reconhecer-se pouco valor ao atleta paralímpico. Através da análise de conteúdo a um jornal diário português, nos anos de 1996 e 2000, anos dos Jogos

Paralímpicos de Atlanta e de Sydney, procurámos perceber qual o valor do atleta com deficiência e se ao longo desses anos existiram alterações nesse valor. A categorização inerente à análise de conteúdo realizou-se a priori e a posteriori, surgindo um sistema categorial constituído pelas categorias (i) nacionalismo, (ii) atleta com deficiência, (iii) prova, (iv) apoio ao atleta e (v) público. A análise de imprensa efectuada revelou um aumento significativo no número de notícias, parecendo demonstrar uma mudança de atitude da sociedade face ao atleta com deficiência. Porém, este não é valorizado sob o ponto de vista estético, mas sim em relação aos resultados obtidos. Na realidade, o resultado e o recorde parecem assumir uma grande importância, podendo afirmar-se que o desporto para pessoas com deficiência se encontra enquadrado na lógica do desporto moderno, esperando-se que o atleta incorpore o homem sem limites.

\section{ABSTRACT}

The Value of the Athlete with Disability. An Analysis through a Portuguese Daily Newspaper

The practice of sports for disabled people has increased significantly. Paralympics Games (its maximum symbol) are a sound evidence. In spite of this, these competitions did not have enough mass media coverage, what suggests a neglect of the actual importance of paralympic movement and their representatives. Using content analysis, a Portuguese daily newspaper of the years 1996 and 2000, covering Atlanta and Sydney Paralympics Games, we investigated the value placed on athletes with disability as well as if there has been any significant change in the way society views them. A priori and a posteriori content analysis pointed out the presence of five categories, namely: (i) nationalism, (ii) athlete with disability, (iii) competition, (iv) athlete's support and $(v)$ public. There has been a significant improvement in the number of reports, which might demonstrate a different attitude in relation to these athletes. However, they are not valued aesthetically, but mainly through their accomplishment. Accomplishment and records seem to get an outstanding importance, suggesting that this kind of sport fits into the logic of modern sport, where the athlete is expected to incorporate a man without limits.

Key Words: athlete with disability, Paralympics Games, press.

Palavras-chave: atleta com deficiência, Jogos Paralímpicos, imprensa. 


\section{INTRODUÇÃo}

A prática de desporto por pessoas com deficiência é, há muito, uma realidade, tendo o desporto adaptado evoluído de forma acentuada nos últimos tempos. De facto, o desporto para pessoas com deficiência tem vindo a desenvolver-se quantitativa e qualitativamente tendo, actualmente, um alcance muito para além da terapia, como é o caso do rendimento. A prova disso mesmo é a existência dos Jogos Paralímpicos (JP), que representam o símbolo máximo do desporto para pessoas com deficiência e que já partilham a mesma organização dos Jogos Olímpicos (JO).

Com 45 anos de história, os JP são considerados o segundo maior evento desportivo a seguir aos JO, pelo número de dias de competição, pelo número de modalidades desportivas que envolve, pelo número de países presentes e, também, por se revelarem a expressão de espectáculo de alta qualidade com a singularidade de atrair espectadores, mass media e patrocinadores ${ }^{(8)}$. Com efeito, temos que reconhecer que há um trajecto muito estimulante, mas não isento de escolhos, entre os primeiros Jogos de Stoke Mandeville, realizados sob a inspiração de Ludwig Guttmann, em Julho de 1948, e os XII JP, levados a cabo em Atenas, no ano de 2004. Entre os atletas amadores do Hospital de Stoke Mandeville e os atletas semi-profissionais e profissionais que competiram na Grécia há, para além das diferenças nítidas do reconhecimento público, a evidência de que a deficiência não é a parte que determina, única e exclusivamente, a pessoa portadora de uma deficiên$\mathrm{cia}^{(9)}$. Contudo, e apesar de toda esta evolução, as competições (nacionais e internacionais) para pessoas com deficiência acontecem, frequentemente, quase na ausência total de público e sem a devida divulgação por parte da comunicação social, parecendo não haver interesse em relatar os seus feitos, por vezes admiráveis(21). Na perspectiva de Brittain(6), esta falta de cobertura dos JP está implicada no parco reconhecimento das capacidades dos atletas com deficiência. Ao falharem a cobertura destes jogos, os mass media, efectivamente, reforçam a mensagem de que o desporto adaptado, mesmo ao nível de competições internacionais, não é interessante e não merece atenção(6).
Numa sociedade tão influenciada pelos mass media como a contemporânea ocidental, a imprensa pode exercer um enorme impacto no nosso conhecimento, atitudes e políticas públicas no que diz respeito a variados assuntos. Esta influência pode aumentar o conhecimento e promover consciência social acerca da deficiência. Todavia, pode igualmente divulgar informação errada e reforçar estereótipos negativos ${ }^{(17)}$. Tendo em conta que as mensagens da imprensa parecem ser o produto e o reflexo da grande maioria dos sistemas sociais, bem como das suas formas de pensar e agir $(5,7,13)$, podemos, eventualmente, considerar que tanto a fraca adesão, como a pouca mediatização sofram uma influência mútua, revelando uma desvalorização do atleta paralímpico. Neste contexto, apesar do desporto paralímpico despertar emoção, espectáculo, beleza, esforço e vontade de superação(2), é de questionar o tipo de valores que a sociedade atribui aos atletas com deficiência e se esses mesmos valores terão sofrido alterações ao longo das últimas décadas. Na realidade, pode afirmar-se que os maiores obstáculos para as pessoas com deficiência não são as suas limitações intelectuais ou físicas, mas as atitudes da sociedade em relação à deficiência e a sua contínua discriminação(26). Face ao exposto, os objectivos deste estudo foram: (i) saber qual o valor do atleta com deficiência, difundido pela imprensa, na sociedade portuguesa e (ii) verificar se houve alterações nesse valor e quais. Para tal, efectuou-se uma análise de imprensa através da qual se pretendeu conhecer a informação existente nos jornais, bem como compreender a forma como essa informação é tratada.

Efectivamente, parece não haver dúvidas quanto ao facto de que os mass media são importantes na modelação da noção do mundo para além da nossa experiência directa do mesmo(10), uma vez que se constituem num dos grandes agentes de socialização. Isto é, são também agentes de promoção e inculcação dos valores, normas e condutas vigentes em cada sociedade.

Quando nos reportamos aos valores, tomamos como referência Patrício(23), para quem os mesmos representam os desejos despertados pelas coisas. Ainda de acordo com o mesmo autor, são várias as ordens de valores, nomeadamente, a vital, a prática, a hedonística, a estética, a lógica, a ética e a religiosa, sendo 
que a cada momento da história e a cada espaço social corresponderá uma diferente hierarquia axiológica nestas ordens de valores. Por conseguinte, podemos desde já avançar com a ideia de que na sociedade ocidental contemporânea impera a relatividade, a pluralidade e a diversidade em todos os campos de acção humana(15), resultando numa verdadeira labilidade axiológica. Não obstante, apesar desta diversidade, parece ainda verificar-se uma atitude generalizada de quase rejeição face ao diferente, materializando-se este fenómeno principalmente na discriminação de grupos minoritários e/ou diferentes(22).

\section{METODOLOGIA}

A primeira operação a realizar para alcançar os objectivos propostos foi seleccionar o corpus de estudo que, tal como referido, se direccionou para os meios de comunicação social, uma vez que estes parecem exercer uma poderosa influência sobre as pessoas(24), reforçando algumas normas e atitudes já existentes $(25,26)$. No entanto, e porque os meios de comunicação social representam uma área muito ampla, surgiu a necessidade de seleccionar, entre os que apresentam maior impacto - rádio, televisão e imprensa -, aquele que fosse mais viável sob o ponto de vista da operacionalidade. Por conseguinte, a nossa opção recaiu sobre a imprensa, dado que este órgão de informação possui uma vasta quantidade de temas passíveis de serem arquivados e preservados ao longo do tempo por cópias, ou outras formas, tornando-se mais fácil e acessível a sua consulta(12). Neste sentido, seleccionámos um periódico diário com base nos seguintes critérios: (i) um periódico diário generalista e (ii) um periódico diário com um número de tiragens de impacto significativo a nível nacional. Assim, respeitando os critérios definidos, a nossa escolha incidiu sobre o "Jornal de Notícias". Tendo em conta o tipo de informação a analisar, submetemos o corpus de estudo ao processo analítico denominado de análise de conteúdo, de acordo com os princípios enunciados por Bardin(3), Vala(29), Grawitz(16) e Silverman(27).

Quanto ao período de análise, seleccionou-se os JP como o momento oportuno para efectuar pesquisa, dada a sua grandiosidade e importância social e por ser considerado o maior evento desportivo para a elite dos atletas com deficiência e o segundo maior logo a seguir aos $\mathrm{JO}^{(11)}$. Os períodos de observação foram escolhidos de acordo com a data do evento desportivo, ou seja, seleccionando a semana de ocorrência do evento e abrangendo as duas semanas precedentes e subsequentes ao mesmo. Este período mais alargado permitir-nos-ia perceber, através da presença/ausência(3), a importância dada pela imprensa ao evento. Por conseguinte, no que concerne aos JP em Atlanta, que decorreram entre os dias 15 e 25 de Agosto de 1996, o período de observação foi estabelecido entre os dias 1 de Agosto e 8 de Setembro. Relativamente aos JP de Sydney, realizados entre 19 e 29 de Outubro de 2000, o período de observação decorreu entre os dias 3 de Outubro e 12 de Novembro. Assim sendo, o corpus de estudo é constituído por todos os artigos relacionados com os JP nos anos de 1996 e 2000, datas correspondentes aos Jogos de Atlanta e Sydney. Pese embora não façam parte do corpus os jornais sem notícias relativas aos eventos, esse foi um aspecto considerado aquando da análise.

Seguidamente, procedeu-se à leitura flutuante do corpus de estudo, assumindo a análise de conteúdo as suas duas funções, ou seja, a confirmatória e a heurística. Assim, com base na revisão bibliográfica, realizou-se parte da categorização - a priori - e após uma exploração mais aprofundada do corpus, efectuou-se a restante categorização - a posteriori. Após definido o sistema categorial, o qual é constituído pelas categorias (i) nacionalismo, (ii) atleta com deficiência, (iii) prova, (iv) apoio ao atleta e (v) público, buscaram-se as unidades de registo e de contexto que sugerissem as categorias criadas.

Finalmente, no que diz respeito à unidade enumeração, optou-se pela análise da presença/ausência e da frequência. De facto e de acordo com Bardin(3), a simples presença ou ausência de determinada unidade pode ser significativa, funcionando como um indicador. Adicionalmente, uma determinada unidade poderá ser tão mais importante quanto maior é a sua frequência.

\section{Justificação das categorias}

Nacionalismo - A pertinência desta categoria fundamenta-se no facto de se pretender estudar o atleta num contexto internacional, nomeadamente o paralímpico, permitindo, consequentemente, compreen- 
der o modo como a imprensa se reporta ao atleta com deficiência em termos de identificação nacional. Com efeito, o termo nacionalismo está directamente relacionado com o patriotismo, ou seja, com a preferência pelo que é próprio da nação a que se perten$\mathrm{ce}^{(1)}$. Na realidade, tendo em conta que vivemos na era da globalização, processo a partir do qual se denota uma tendência para escamotear a preponderância do Estado-Nação face ao mundo global, é provável um efeito da importância acrescida na instância cultural e nacional nas sociedades industrializadas. Assim sendo, consideramos fundamental perscrutar se, também no âmbito dos paralímpicos, é evidente esse efeito acrescido da instância cultural nacional. Atleta com deficiência - A forma como a informação, relativamente ao atleta com deficiência, é tratada poderá ser um importante indicador do valor que este assume perante a sociedade. Acrescente-se, ainda, que dentro desta categoria surgem como subcategorias o perfil do atleta, bem como a descrição da sua condição física. No que concerne ao perfil do atleta, a classificação desportiva dos atletas com deficiência torna-se relevante, dado que é a partir desta que os atletas competem em igualdade de circunstâncias. Para além disso, pretendeu-se saber se o tipo de deficiência condiciona, ou não, o modo como a notícia é desenvolvida.

Prova - As modalidades desportivas para pessoas com deficiência são todo o conjunto de experiências desportivas modificadas ou especialmente concebidas para estes indivíduos ${ }^{(7)}$. Será a partir desta alteração, com base na qualificação desportiva aliada à classificação dos atletas, que se pretende garantir que os JP reflictam e promovam a qualidade e a universalidade ${ }^{(8)}$. Não obstante, esta poderá ser uma forma de retirar alguma espectacularidade às provas, já que promove o aumento do seu número e torna o próprio evento mais moroso do que eventualmente seria de esperar de um espectáculo.
Fazem parte desta categoria cinco subcategorias: classificações/resultados, recordes, prospecções/expectativas, programa e descrição da prova.

Apoio ao atleta - Com esta categoria procurou-se apreender se as notícias abordam assuntos tão diversos, como questões relacionadas com as dificuldades no acesso e desenvolvimento da prática, ou as próprias condições in loco da comitiva portuguesa. Com efeito, havendo apoio institucional, associativo-desportivo e mesmo social, percebe-se a existência da valorização do atleta com deficiência ${ }^{(17)}$. Neste sentido, esta categoria tem como subcategorias o apoio institucional, o apoio desportivo e o apoio social. Público - O público é uma categoria fundamental, uma vez que poderá evidenciar o maior, o menor ou até o inexistente interesse da parte da sociedade pelo desporto para pessoas com deficiência. De facto, a referência a uma maior ou menor afluência aos jogos e outras situações relacionadas com os atletas portugueses será um indicador do interesse pelos JP. Isto porque, pese embora os eventos desportivos para pessoas com deficiência possam despertar o espectáculo(2), acontecem normalmente na ausência de público, provavelmente por falta de emoção e de identificação(21).

\section{APRESENTAÇÃO E DISCUSSÃO DOS RESULTADOS}

A apresentação e discussão dos resultados encontrase estruturada em três partes: na primeira, é efectuada uma análise centrada no número de notícias e na sua respectiva localização; na segunda, analisa-se o tipo de fotografias; finalmente, na terceira, são discutidas as diferentes categorias criadas. Todos os quadros apresentados terão em conta os três tempos considerados neste trabalho, ou seja, antes, durante e após os JP de Atlanta e de Sydney.

Assim sendo, o quadro 1 mostra a frequência de notícias nesses três tempos, de acordo com três zonas do jornal, nomeadamente a capa principal, a capa de suplemento desportivo e o corpo do jornal.

Quadro 1: Frequência de notícias acerca dos Jogos Paralímpicos e a sua respectiva localização (capa principal, capa de suplemento desportivo e corpo do jornal)

\begin{tabular}{|c|c|c|c|c|c|c|c|c|c|c|}
\hline \multirow[b]{2}{*}{ Localização da notícia } & \multicolumn{5}{|c|}{1996} & \multicolumn{5}{|c|}{2000} \\
\hline & Antes & Durante & Após & Sub/Total & Total & Antes & Durante & Após & Sub/Total & Total \\
\hline Capa principal & 0 & 0 & 0 & 0 & \multirow{3}{*}{6} & 0 & 1 & 0 & 1 & \multirow{3}{*}{34} \\
\hline Capa de suplemento & 0 & 0 & 1 & 1 & & 0 & $?$ & 2 & 9 & \\
\hline Corpo do jornal & 0 & 3 & 2 & 5 & & 3 & 19 & 2 & 24 & \\
\hline
\end{tabular}


Ao observarmos o quadro 1, verificamos a presença de notícias em ambos os anos, durante e após o evento, no entanto, apenas em 2000 se verificou a presença de notícias antes do evento. Esta diferença parece ser um indicador acerca da maior importância atribuída ao evento em 2000, uma vez que é dada maior importância pela imprensa a um fenómeno de acordo com a sua proximidade(7). Esta alteração, ao nível da imprensa, poderá indiciar uma mudança dos interesses do público-alvo, dado que os meios de comunicação social tentam ir ao encontro dos interesses e curiosidades do mesmo, acabando por actuar como um espelho da sociedade(7). Por outro lado, esta alteração poderá sugerir uma mudança na mentalidade patente, já que os meios de comunicação social podem exercer uma poderosa influência sobre as pessoas ${ }^{(6)}$. No entanto, é de referir que, embora surjam notícias após o evento em ambos os anos - 3 e 4 dias respectivamente -, observa-se que os JO são noticiados até cerca de duas semanas após o seu encerramento(25).

Quanto à localização das notícias, é possível constatar a ausência, em 1996, de notícias na capa principal, embora se tenha evidenciado a respectiva presença na capa de suplemento desportivo e respectivo corpo do jornal. No ano de 2000, a presença é visível em todas as partes do jornal, inclusivamente na capa principal do jornal $(n=1)$. Esta presença refere-se a uma medalha alcançada por um atleta português na modalidade de Boccia. Por conseguinte, pensamos que estes resultados poderão ser uma evidência da maior vontade, por parte da imprensa, em conduzir o público a ler as notícias relativas aos JP, na medida em que a decisão do leitor em ler, ou não, um artigo poderá ter a ver com a apresentação do mesmo(25). Adicionalmente, os números expressos neste quadro indicam-nos uma maior quantidade total de informação existente em $2000(n=34)$, nos três momentos de observação, comparativamente com o ano de $1996(n=6)$. Assim sendo, esta diferença parece revelar que o jornal pretende, em 2000, manter o público informado sobre esta competição e, nesse caso, as circunstâncias poderão ter mudado desde 1996, altura em que a comunicação social parecia não efectuar a devida divulgação destas competições(21). Com efeito, além de escassa, a divulgação de assuntos sobre o paralimpismo só tende a acontecer em períodos muito próximos à data do evento, parecendo corroborar a ideia de que os media não se encontram sensibilizados para o fenómeno(7). Para além do referido, constatou-se uma presença, quase diária, de uma referência aos JP de Sydney na capa de suplemento desportivo que conduzia a uma notícia mais extensa e pormenorizada acerca do evento, não se tendo o mesmo verificado nos de Atlanta. Se o jornal apresenta mais informação sobre o evento em 2000 então é porque, presumivelmente, a sociedade também se interessa mais pelo mesmo, o que sugere uma mudança na atitude da mesma. Por outro lado, apesar de se constatar que a área atribuída a estes destaques, nomeadamente na capa principal e no suplemento, é reduzida, também o é noutras modalidades desportivas que não o futebol profissional.

Outro aspecto que deve ser salientado é o facto de em 2000 existir um espaço (geralmente uma página) dedicado ao tema JP, enquanto que em 1996 as notícias surgiam pelo meio do jornal e, frequentemente, escamoteadas por um título, como por exemplo: "Fernanda Ribeiro aquece para recorde". Um título que em nada sugere a existência de qualquer referência aos atletas paralímpicos. Desta forma, parece estar ainda mais evidenciada a evolução ocorrida entre 1996 e 2000, já que neste ano as notícias reportamse directa e explicitamente aos paralímpicos. Quanto às fotografias existentes, o quadro 2 mostra a sua ausência/presença e a sua frequência.

Quadro 2: Ausência/presença e frequência de fotografias acerca dos Jogos Paralímpicos.

\begin{tabular}{|l|c|c|c|c|c|c|c|c|}
\hline & \multicolumn{9}{|c|}{1996} & 2000 \\
\hline Fotografias & Antes & Durante & Após & Total & Antes & Durante & Após & Total \\
\hline & $\mathrm{A} / 0$ & $\mathrm{~A} / 0$ & $\mathrm{P} / 1$ & $\mathrm{P} / 1$ & $\mathrm{P} / 2$ & $\mathrm{P} / 12$ & $\mathrm{P} / 1$ & $\mathrm{P} / 15$ \\
\hline
\end{tabular}


Ao analisarmos o quadro 2, verifica-se que em 1996 só surgem fotografias após o evento $(n=1)$, enquanto que no ano de 2000 existem fotografias antes $(n=2)$, durante $(n=12)$ e após o evento $(n=1)$, perfazendo um total de quinze fotografias. Assim sendo, este aumento parece contrariar Castro e Garcia (21), quando defendem que ninguém ousa mostrar o que socialmente é diferente. Não obstante, e porque existem deficiências que ao nível da aparência física parecem impressionar mais do que outras, analisaram-se em quais deficiências se centravam as fotografias encontradas. Os resultados estão registados no quadro 3 .

Quadro 3: Tipo de deficiência observada nas fotografias.

\begin{tabular}{|l|c|c|}
\hline Fotografias & $\mathbf{1 9 9 6}$ & $\mathbf{2 0 0 0}$ \\
\hline Cegos & 0 & 8 \\
\hline Cadeiras de rodas & 0 & 2 \\
\hline Paralisia cerebral & 0 & 2 \\
\hline Amputados & 0 & 1 \\
\hline Outras fotografias & 1 & 2 \\
\hline Total & 1 & 15 \\
\hline
\end{tabular}

Neste quadro é possível verificar a existência de um total de oito fotografias de atletas cegos, duas de atletas em cadeira de rodas, duas de atletas com paralisia cerebral e uma de um atleta amputado. Estes resultados diferem de outros estudos semelhantes $(25,28)$, nos quais predominam fotografias de atletas em cadeira de rodas. Em nosso entender, a razão pela qual a maioria das fotografias é de atletas cegos poderá estar relacionada com o facto desta deficiência ser a menos perceptível ao nível fotográfico. Isto é, o atleta cego é o que mais se assemelha ao atleta dito normal, não causando, por isso, um impacto tão forte como a fotografia de um atleta em cadeira de rodas ou com paralisia cerebral. Com efeito, a presença visível da deficiência é crucial para identificar alguém como sendo realmente uma pessoa com deficiência ${ }^{(28)}$. Porém, a frequência referida pode estar associada ao facto da maior parte das vitórias conquistadas em Sydney corresponderem a estes atletas, sendo, por esse motivo, natural que a imprensa retrate os vencedores, em particular os portugueses. Para além disso, surgem fotografias dos atletas com paralisia cerebral, vencedores nas provas singulares de Boccia (BC3), cuja classe inclui os atletas com a deficiência mais severa e a fisicamente mais visível.

Para a análise do conteúdo das fotografias constaram dois pontos essenciais: o atleta em prova (fotografia tipo activo) e o atleta fora da competição (fotografia do tipo não activo). O resultado desta análise encontra-se no quadro 4.

Quadro 4: Representação fotográfica de atletas em poses tipo activo e tipo passivo.

\begin{tabular}{|lc|c|}
\hline Fotografias & $\mathbf{1 9 9 6}$ & $\mathbf{2 0 0 0}$ \\
\hline Activo & 0 & 10 \\
\hline Passivo & 1 & 5 \\
\hline Total & 1 & 15 \\
\hline
\end{tabular}

Observa-se que em 1996 existe apenas uma fotografia do tipo passivo, cujo conteúdo se reporta à chegada ao aeroporto dos atletas, o que parece indicar alguma negação da imagem da pessoa com deficiência, conforme é defendido por vários autores $(6,17,21)$. No que diz respeito a 2000 , de um total de quinze fotografias contabilizadas, dez correspondem a fotografias do tipo activo, enquanto cinco são do tipo passivo. Estes dados parecem contrariar os de Thomas e Smith(28), já que a maioria das fotografias do seu estudo se remetem ao tipo passivo, contrapondo a habitual associação entre a pessoa com deficiência e passividade.

À excepção de uma fotografia de um atleta amputado, todas as outras fotografias que focam o atleta em prova são de atletas cegos. Quanto às fotografias relativas às vitórias dos atletas de Boccia (paralisia cerebral) e de uma atleta da Natação (amputada), reportam-se a momentos fora da prova (tipo passivo). Ou seja, em ambos os casos quando se encontravam no pódio e escondendo a sua deficiência. A reforçar esta ideia, a única fotografia do tipo activo do Boccia apresenta os atletas de costas, não permitindo, por isso, ver os mesmos. Neste contexto, parecem fazer sentido as ilações retiradas em estudos anteriores $(18,25,28)$, nos quais os atletas mais retratados são, geralmente, os em cadeira de rodas, fotografados da cintura para cima, de forma a que não seja tão perceptível a sua deficiência. Esta é, talvez, a maior evidência de que a 
nossa sociedade ainda não está sensibilizada para aceitar a imagem da pessoa com deficiência. Talvez a imprensa não mostre porque o público não aprecia, funcionando, deste modo, como um indicador do que a sociedade quer ou não quer ver. Assim sendo, ao esconder-se a deficiência podemos considerar que existe alguma tendência em aproximar os atletas com deficiência aos ditos normais através da imagem, retirando-lhes parte da sua identidade. Eventualmente sem intenção, a imprensa poderá estar a potenciar uma aparente rejeição já existente, parecendo existir uma tentativa de se assemelhar a imagem deste atleta com o dito normal.

No que concerne às categorias criadas e anteriormente referidas, a análise começa pelo

Nacionalismo. Para esta categoria, e através das unidades encontradas, verificamos que, embora mais evidente em 1996, em ambos os anos "o atleta Português...” está perfeitamente identificado. De tal modo que, por vezes, embora de forma metafórica, o atleta deixa de ser pessoa, passando a encarnar o próprio país, pois "Portugal conquistou...", ou "Portugal assegurou...". Adicionalmente, esta identificação surge no âmbito da vitória, até porque o desporto se assume como um ritual simbólico de lutas intermináveis entre grupos, entre nações ${ }^{(21)}$. De facto, a linguagem da imprensa invade-nos diariamente com frases de cariz bélico, exaltando a vitória dos nossos e humilhando a derrota dos outros(21). Nesse sentido, é de aceitar que em ambos os anos se tenha dado destaque às vitórias do país, uma vez que as mesmas enaltecem e elevam o que é nosso, face aos outros. No entanto, em 2000, este nacionalismo também acontece no âmbito de algumas derrotas, pois alguém “... eliminou Portugal da prova...”, ao contrário de 1996, cujas notícias apenas identificam Portugal com as vitórias, o ranking e o número de medalhas obtidas. Na realidade, os dados do nosso estudo parecem demonstrar uma grande importância atribuída ao sucesso nacional, sendo que as principais diferenças entre os dois anos se notam em relação à maior importância atribuída em 1996 à vitória nacional em detrimento do atleta, pois “Portugal obteve...". Em 2000, apesar desse nacionalismo estar presente, ao noticiar-se que "o atleta José Firmino deu ontem a Portugal...”, assume-se a sua vitória como a de todos os portugueses, mas enaltece-se a pessoa humana que a alcançou. O mesmo é discutido por Schantz e Gilbert(25), estando os nossos dados relativos a 1996 de acordo com a descrição acerca do tratamento de informação para os JP de Atlanta, efectuada pelos autores. Adicionalmente, os dados obtidos relativamente a Sydney 2000 estão em consonância com os de Thomas e Smith(28), pois também no seu estudo é realçado este nacionalismo, mas centrado no mérito do atleta. Desta forma, verificamos que o sentimento nacionalista, enaltecido na imprensa portuguesa, não foi exclusivo, uma vez que tal é reportado noutros estudos $(25,28)$.

O quadro 5 refere-se à frequência e presença/ausência de referências às subcategorias que constituem a categoria designada de Atleta com Deficiência.

Quadro 5: Ausência/presença e frequência de referências às subcategorias Perfil do Atleta e Condição Física na categoria Atleta com Deficiência.

\begin{tabular}{|c|c|c|c|c|c|c|c|c|c|c|}
\hline & \multicolumn{5}{|c|}{1996} & \multicolumn{5}{|c|}{2000} \\
\hline $\begin{array}{l}\text { Atleta com } \\
\text { deficiência }\end{array}$ & Antes & Durante & Após & Sub/Total & Total & Antes & Durante & Após & Sub/Total & Total \\
\hline Perfil do atleta & $\mathrm{A} / 0$ & $\mathrm{~A} / 0$ & $\mathrm{~A} / 0$ & $\mathrm{~A} / 0$ & \multirow{2}{*}{$\mathrm{A} / 0$} & $\mathrm{~A} / 0$ & $\mathrm{P} / 11$ & $\mathrm{~A} / 0$ & $\mathrm{P} / 11$ & \multirow{2}{*}{$\mathrm{P} / 32$} \\
\hline Condição física & $\mathrm{A} / 0$ & $\mathrm{~A} / 0$ & $\mathrm{~A} / 0$ & $\mathrm{~A} / 0$ & & $\mathrm{P} / 14$ & $\mathrm{P} / 7$ & $\mathrm{~A} / 0$ & $\mathrm{P} / 21$ & \\
\hline
\end{tabular}

Ao analisarmos o quadro 5 verificamos a ausência, em 1996, de referências a qualquer uma das subcategorias consideradas nos espaços temporais escolhidos, corroborando a análise da categoria anterior, ou seja, um manifesto desinteresse pelo atleta, dando-se primazia ao resultado por ele alcançado, quando positivo. No entanto, em 2000 constata-se a presença desta categoria, evidenciada pelas duas subcategorias - Perfil do Atleta e Condição Física.

No que concerne ao Perfil do Atleta, observa-se a sua presença apenas durante os JP $(n=11)$. Esta subcategoria dispõe de informação acerca do atleta, tal como 
a sua naturalidade, data de nascimento, nome e ainda o seu percurso desportivo. É possível que as unidades para esta subcategoria surjam somente durante o evento, uma vez que a mesma foca os atletas vencedores. Apesar desta subcategoria apenas se reportar a esses atletas, denota-se já a intencionalidade, por parte da imprensa, em dá-los a conhecer um pouco mais, tornando o significado daquela vitória mais compreensível para o leitor.

Adicionalmente, esta informação não se centra exclusivamente na deficiência, destacando, igualmente, os resultados mais importantes. Desta forma, os nossos dados pareceram contrariar os de vários estudos $(25,28)$, uma vez que o atleta é descrito de forma similar aos atletas ditos normais e, inclusive, associado a figuras belas, como é o caso da nadadora Susana Barroso comparada a uma "sereia de prata". Neste contexto, parece consubstanciar-se uma das características marcantes do nosso tempo, a centrali- zação na pessoa(14). Para além disso, como esta informação se reporta aos atletas vencedores, poderá significar uma incorporação do princípio do rendimento - característica marcante do desporto moderno - no desporto para pessoas com deficiência. Em relação à subcategoria Condição Física constatamos, em 2000, a sua presença antes $(n=14)$ e durante $(n=7)$ os JP e uma ausência após os mesmos. Na realidade, a presença da condição física dos atletas ao longo dos momentos referidos faz sentido, uma vez que o resultado da prova depende da mesma, o que revela, consequentemente, uma importância atribuída ao resultado. Para além disso, parece ser inequívoca a intenção, por parte da imprensa, em fornecer informação acrescentada acerca da condição física do atleta.

No quadro 6 expõe-se a frequência e a ausência/presença das referências às subcategorias da categoria Prova.

Quadro 6: Ausência/presença e frequência de referências às subcategorias Classificações/Resultados, Recordes, Prospecções/Expectativas, Programa da Competição e Descrição da Prova na categoria Prova.

\begin{tabular}{|c|c|c|c|c|c|c|c|c|c|c|}
\hline & & & 1996 & & & & & 2000 & & \\
\hline Prova & Antes & Durante & Após & Sub/Total & Total & Antes & Durante & Após & Sub/Total & Total \\
\hline $\begin{array}{l}\text { Classificações/ } \\
\text { Resultados }\end{array}$ & $\mathrm{A} / 0$ & $\mathrm{P} / 11$ & $\mathrm{P} / 6$ & $P / 17$ & \multirow{5}{*}{$\mathrm{P} / 24$} & $\mathrm{~A} / 0$ & $\mathrm{P} / 68$ & $\mathrm{P} / 6$ & $P / 74$ & \multirow{5}{*}{$P / 154$} \\
\hline Recordes & $\mathrm{A} / 0$ & $\mathrm{P} / 1$ & $\mathrm{~A} / 0$ & $\mathrm{P} / 1$ & & $\mathrm{~A} / 0$ & $\mathrm{P} / 12$ & $\mathrm{~A} / 0$ & $\mathrm{P} / 12$ & \\
\hline $\begin{array}{l}\text { Prospecções/ } \\
\text { Expectativas }\end{array}$ & $\mathrm{A} / 0$ & $\mathrm{P} / 3$ & $\mathrm{P} / 3$ & $\mathrm{P} / 6$ & & $\mathrm{P} / 3$ & $\mathrm{P} / 35$ & $\mathrm{~A} / 0$ & $\mathrm{P} / 38$ & \\
\hline $\begin{array}{l}\text { Programa da } \\
\text { competição }\end{array}$ & $\mathrm{A} / 0$ & $\mathrm{~A} / 0$ & $\mathrm{~A} / 0$ & $\mathrm{~A} / 0$ & & $\mathrm{~A} / 0$ & $\mathrm{P} / 11$ & $\mathrm{~A} / 0$ & $\mathrm{P} / 11$ & \\
\hline $\begin{array}{l}\text { Descrição da } \\
\text { prova }\end{array}$ & $\mathrm{A} / 0$ & $\mathrm{~A} / 0$ & $\mathrm{~A} / 0$ & $\mathrm{~A} / 0$ & & $\mathrm{~A} / 0$ & $\mathrm{P} / 18$ & $\mathrm{P} / 1$ & $\mathrm{P} / 19$ & \\
\hline
\end{tabular}

No que diz respeito à subcategoria Classificações/ Resultados, tanto em 1996 como em 2000, verifica-se uma presença durante $(n=11 / n=68)$ e após $(n=6 / n=6)$ os mesmos. O grande número de referências em 2000 parece indiciar elevada centralização sobre o resultado. De qualquer forma, em ambos os anos, é esta subcategoria que apresenta maior número de referências, o que mais uma vez reforça a ideia de que o desporto para pessoas com deficiência terá incorporado a lógica do desporto moderno(21), no qual o resultado assume uma grande importância.

Efectivamente, quando nos debruçamos sobre o con- teúdo das notícias, os resultados obtidos pelos atletas, bem como os recordes alcançados, demonstram isso mesmo. Assim, em 1996, as notícias relativa aos resultados, apesar de referirem o nome do atleta, centram-se exclusivamente nas medalhas, tal como é ilustrado nos exemplos seguintes: “... Carlos Amaral conquista bronze em Atlanta" ou "Portugal conquistou, ontem, duas medalhas de ouro e uma de prata...". Em 2000, apesar das notícias focarem as medalhas, também salientam vitórias sem medalhas, conforme se demonstra no excerto seguinte: "Portugal começou ontem da melhor forma a participação nos Jogos 
Paralímpicos de Sydney 2000, vencendo o Brasil...”. Dão, ainda, destaque a algumas derrotas “... um dia de derrotas... equipa de Futebol perdeu (0-3) com a Ucrânia...", sem que se esqueça que o atleta "Carlos Amaral Ferreira... alcançou o $2^{\circ}$ lugar". Na realidade, constatase que em 2000, qualquer que seja o resultado, este é divulgado, demonstrando uma valorização quer da prova, quer dos atletas. Com efeito, ao tomarmos em consideração registos como "Fátima Matos bem sucedida... apesar de quarta da sua série, conseguiu um dos melhores tempos", percebe-se que, pese embora o resultado não tenha sido uma vitória, terá sido uma boa prova. Ou seja, embora o atleta não tenha alcançado um título, não deixa de se enaltecer a sua boa prestação, dado que se procura atenuar a derrota e valorizar a pessoa que a protagonizou. Apesar desta pretensa valorização, na perspectiva de Shell e Duncan(26), esta representa uma certa condescendência, já que quando as notícias se reportam a atletas sem deficiência, os mesmos são criticados pelas suas falhas.

No que concerne à subcategoria Recordes denota-se, em 1996, a sua presença apenas durante os JP $(n=1)$, enquanto que em 2000 , apesar dos registos acontecerem somente durante o evento, o número é claramente superior $(n=12)$, algo que poderá ser explicado pelo facto do número de recordes em 1996 ter sido inferior ao de 2000. Reitera-se, portanto, a analogia entre o desporto para pessoas com deficiência e o desporto de alto rendimento dos atletas ditos normais. Os exemplos seguintes ilustram isso mesmo: “... ouro conquistado por Gabriel Potra, que estabeleceu um novo recorde paralímpico..."; "quarteto português estabeleceu novo máximo nos $4 \times 400$ metros"; "a nadadora Susana Barroso... bateu o recorde nacional que lhe pertencia...".

Em relação à subcategoria Prospecções/Expectativas, em 1996 nota-se ausência antes do evento e presença durante e após o mesmo. Já no ano de 2000 , observamos a presença antes e durante os jogos e a sua ausência após os mesmos. Esta presença, em ambos os anos, durante o evento justifica-se por si própria, já que é de aceitar que existam expectativas e prospecções em redor das provas. No entanto, em 2000 estes números foram superiores, apresentando esta subcategoria um total de trinta e oito unidades, das quais três se verificam antes do evento e trinta e cinco durante o mesmo, corroborando, assim, a maior importância atribuída ao fenómeno em 2000. Não obstante, é provável que os resultados obtidos pelos atletas em Atlanta possam ter influenciado maiores expectativas em torno dos Jogos de Sydney, na medida em que a existência de informação anterior sobre um facto permite valorizar, ou não, o mesmo(25). É, ainda, de salientar que as notícias de 2000 surgiam com maior intensidade, ou seja, não só o número é superior, como também e, principalmente, o conteúdo é mais explícito, pois “... a equipa lusa vai entrar para ganhar..." ou, ainda, a referência aos atletas que "... abrem boas perspectivas para o seu primeiro teste em solo australiano...”. Adicionalmente, nota-se um optimismo gerado em redor do evento quando se afirma que “... as expectativas são as melhores havendo mesmo a possibilidade de superar as marcas de Atlanta" e, assim sendo, as mesmas são projectadas num sentido mais generalizado, difundindo-se sobre todos os atletas. Deste modo, parece estar patente maior relevância ao evento e também ao atleta com deficiência no ano 2000, uma vez que também se verifica uma maior deposição de esperanças da parte da nação (visível no jornal). Ao constatarmos a existência de expectativas relativamente ao desporto para pessoas com deficiência, anteriormente só verificadas para o desporto de alto rendimento, que movimenta maiores interesses económicos(19), apuramos uma cada vez maior semelhança entre ambos. Outra subcategoria considerada foi o Programa da Competição que, conforme se observa, só está presente em $2000(n=11)$. Esta subcategoria está ausente antes e após os mesmos, pois o objectivo deste tipo de notícia é informar a data e a hora das provas. Por conseguinte, parece manifestar-se uma intenção de manter o público informado, bem como permitir ao leitor saber quais as provas em que Portugal ou os atletas portugueses participavam. Neste contexto, a ausência verificada em 1996 revela-se pouco positiva, já que não se revela essa mesma tendência.

Finalmente, no que concerne à Descrição da Prova, com ausência no ano de 1996, mas presente em $2000(n=19)$, quase sempre se descrevem as provas com alusão aos atletas envolvidos, denotando-se um certo cuidado para cada atleta e reforçando a intencionalidade em manter o público informado. Embora se faça sentir um determinado nacionalismo, ou seja, 
um destaque para a equipa e representação portuguesa, quando se afirma que “... a selecção Portuguesa demonstrou já algum entrosamento entre os jogadores...”, nota-se, igualmente, a referência ao atleta individual. De facto, "durante a prova o atleta Gabriel Potra... não teve a vida facilitada... mas conseguiu ser melhor do que o chinês...", o que vem confirmar o salientado na categoria Atleta com Deficiência. Ou seja, uma (aparente) maior centralização na pessoa humana, neste caso do atleta protagonista da prova.

De um modo geral, os resultados de 1996 e de 2000 parecem ter contrariado os de Schantz e Gilbert(25), uma vez que estes autores verificaram que o tipo de cobertura efectuada pela imprensa não era especificamente desportiva, reportando-se, sim, a escânda- los e problemas que, na opinião dos autores, se prendem com objectivos comerciais.

Contrariamente, os nossos dados centram-se, em ambos os anos, na divulgação dos resultados, embora em 1996 esta divulgação ocorra especialmente em relação aos bons resultados.

A indicação da deficiência do atleta surge como complemento informativo, dada a classificação específica utilizada para a realização de provas a nível do desporto para pessoas com deficiência. É ainda de acrescentar que a informação em 2000 permite não só dar a conhecer os resultados, como também reconhecer o valor da performance destes atletas, uma vez que frequentemente estas notícias são muito descritivas e minuciosas.

Quadro 7: Ausência/presença e frequência de referências às subcategorias Dados Políticos/Federação e Direitos/Discriminação na categoria Apoio ao Atleta.

\begin{tabular}{|c|c|c|c|c|c|c|c|c|c|c|}
\hline \multirow[b]{2}{*}{ Apoio ao Atleta } & \multicolumn{5}{|c|}{1996} & \multicolumn{5}{|c|}{2000} \\
\hline & Antes & Durante & Após & Sub/Total & Total & Antes & Durante & Após & Sub/Total & Total \\
\hline $\begin{array}{l}\text { Dados políticos/ } \\
\text { Federação }\end{array}$ & $\mathrm{A} / 0$ & $\mathrm{P} / 2$ & $\mathrm{P} / 2$ & $\mathrm{P} / 4$ & \multirow{2}{*}{$\mathrm{P} / 4$} & $\mathrm{P} / 11$ & $\mathrm{P} / 8$ & $\mathrm{P} / 2$ & $\mathrm{P} / 21$ & \multirow{2}{*}{$\mathrm{P} / 32$} \\
\hline $\begin{array}{l}\text { Direitos/ } \\
\text { Discriminacão }\end{array}$ & $\mathrm{A} / 0$ & $\mathrm{~A} / 0$ & $\mathrm{~A} / 0$ & $\mathrm{~A} / 0$ & & $\mathrm{P} / 11$ & $\mathrm{~A} / 0$ & $\mathrm{~A} / 0$ & $\mathrm{P} / 11$ & \\
\hline
\end{tabular}

Quanto à categoria Apoio ao Atleta, e ao observarmos o quadro 7, constatamos que, em 1996, a subcategoria Dados Políticos/Federação está presente durante $(n=2)$ e após $(n=2)$ os JP. Em 2000, encontra-se presente nos três tempos analisados. A presença antes do evento, em 2000, reporta-se a uma recepção feita à delegação portuguesa pelo PrimeiroMinistro, com o intuito de lhes desejar boa sorte antes da sua partida para os JP, o que poderá revelar uma maior atenção dada a estes atletas nesse ano. Em ambos os anos, estas referências remetem-se, maioritariamente, a mensagens das entidades governamentais a felicitar os atletas pelas suas vitórias, mas encontramos, igualmente, a presença de referências a apoios monetários garantidos pelo Estado. Finalmente, a subcategoria Direitos/Discriminação está sempre ausente nos Jogos de Atlanta (1996), enquanto que em 2000 encontra-se presente apenas antes. O que se observa é que a imprensa tornou visível algumas dificuldades sentidas pelos atletas, nomeadamente o caso de Lenine Cunha cuja “... deslocação à Austrália valeu a não renovação do contrato de trabalho...", mostrando, portanto, que a imprensa pode assumir um papel preponderante na mudança de atitudes $(6,7,17)$, designadamente em relação à pessoa com deficiência. Por outro lado, este meio de comunicação social poderá estar a passar a imagem de que a pessoa/atleta com deficiência é uma vítima e que passa por muitas dificuldades, reforçando a ideia de que ocupa uma posição excluída na nossa sociedade(20). Não obstante, é de salientar que, também ao nível de certas modalidades para atletas sem deficiência, parece existir alguma discriminação, inclusive da parte da comunicação social $(4,7)$. A categoria Apoio ao Atleta encontra-se visível em ambos os anos, uma vez que Atlanta 1996 marcou o início de um novo ciclo do desporto para pessoas com deficiência em Portugal. Efectivamente, terá sido neste ano que, pela primeira vez, a delegação paralímpica recebeu apoio financeiro substancial da parte 
do Governo(11). Na realidade, esta tendência parece ter evoluído num sentido positivo, já que em Sydney o apoio sentido foi maior, não só a nível financeiro, como também ao nível social, pois são mais numerosas as referências a felicitações e presença de entidades governamentais no local dos JP. Tal não se terá verificado em 1996, pressupondo, consequentemente, que este evento tem vindo a assumir maior importância ao longo dos últimos anos.

Relativamente à categoria Público, cuja frequência e ausência/presença se encontram representadas no quadro 8, verifica-se que, tanto em 1996 como em 2000, ela está presente durante e após o evento. Contudo, quando analisamos a frequência de notícias, dentro desta mesma categoria, verificamos diferenças entre os dois anos em análise.

Quadro 8: Ausência/presença e frequência de referências à categoria Público.

\begin{tabular}{|c|c|c|c|c|c|c|c|c|}
\hline & \multicolumn{4}{|c|}{1996} & \multicolumn{4}{c|}{2000} \\
\hline Público & Antes & Durante & Após & Total & Antes & Durante & Após & Total \\
\hline & $\mathrm{A} / 0$ & $\mathrm{P} / 1$ & $\mathrm{P} / 2$ & $\mathrm{P} / 3$ & $\mathrm{~A} / 0$ & $\mathrm{P} / 10$ & $\mathrm{P} / 1$ & $\mathrm{P} / 11$ \\
\hline
\end{tabular}

São três as referências em 1996: uma durante o evento e duas após o mesmo; enquanto que em 2000 se encontram dez durante o evento e uma após o mesmo, num total de onze referências. O que verificamos foi que, tanto em 1996 como em 2000, é visível um reduzido número de referências nesta categoria, algo mais evidente no ano de Atlanta, talvez pela baixa adesão do público. Pensamos que a diferença entre os dois anos se prende com o facto de se ter verificado, em 2000, um apoio muito forte por parte da comunidade portuguesa presente na Austrália ao longo dos jogos dado que "em todos os recintos onde se disputavam provas dos portugueses, podiam encontrar-se várias bandeiras verdes e encarnadas e ouvir-se o grito de incentivo "força Portugal!". Com efeito, esse apoio é evidente nas notícias, pois "Paulo Ramos realçou o apoio dos portugueses ao longo do percurso, tendo um deles corrido com a dupla cerca de 500 metros...", referindo-se, inclusivamente, que algumas provas terão proporcionado "... um belo espectáculo às pessoas que encheram as bancadas do Indoor Sports Centre". No entanto, em 1996, as unidades referem-se ao público de uma forma geral, ou seja, “... realizou-se... perante cerca de 50.000 espectadores a cerimónia de encerramento" e, além disso, parecem reflectir a baixa adesão sentida durante este evento, já que “... a competição dos paralímpicos teve o seu início debaixo de uma compensadora presença de público nos estádios...". Atente-se à palavra compensadora. Em nosso entender esta é, provavelmente, uma tentativa camuflada de afirmar que tendo em conta que eram os paralímpicos... até esteve muita gente.
Desta forma, parece fazer sentido o reduzido número encontrado em 1996, uma vez que os atletas com deficiência são, frequentemente, considerados como atletas de segunda classe(26). Por causa desta noção, os feitos de muitos atletas com deficiência ficam por noticiar a um público que espera pela apresentação do desporto por parte dos mass media(26).

O que se observou, relativamente a este facto, foi que a única referência relativa ao número de espectadores em 1996 se reporta à cerimónia de encerramento, enquanto que em 2000 se constatou que "o jogo disputado no centro de futebol do Parque Olímpico da Baía da Homebush, foi assistido por cerca de três mil pessoas...". De facto, em Sydney, e como já referido, verificou-se a presença de público português nos Jogos, não se tendo notado o mesmo em 1996, o que poderá eventualmente dar-nos indicações acerca de uma possível valorização do atleta com deficiência. Não podemos, porém, esquecer que este público, apesar de ser português, vive num contexto diferente do de Portugal, o que poderá ter influenciado os resultados obtidos.

\section{CONCLUSÃO}

A análise de imprensa efectuada revela, em primeiro lugar, um aumento significativo no número de notícias entre 1996 e 2000, parecendo demonstrar uma mudança de atitude da sociedade face ao atleta com deficiência. Esta alteração poderá corresponder a uma maior valorização do mesmo. Isto é, tendo em conta um aumento de informação e descrição das provas, podemos afirmar que, embora ainda muito distante, 
se tenta uma aproximação ao modelo do atleta dito normal. De facto, ao contrário do ano de 1996, em 2000 as notícias referem-se explicitamente aos atletas paralímpicos, revelando que estes são notícia e merecem o devido destaque. No que diz respeito às fotografias, podemos afirmar que quanto menos visível for a deficiência, maior a probabilidade da notícia ser ilustrada com uma fotografia do atleta. Deste modo, parece que a sociedade ainda não é capaz de conceber, num atleta, a condição de pessoa com a deficiência que lhe está inerente. É de considerar, por conseguinte, que a pessoa com deficiência não é valorizada sob o ponto de vista estético. O atleta parece, sim, ser tanto mais valorizado quanto melhores forem os resultados obtidos. De facto, é notória a exaltação da vitória do atleta em ambos os anos, identificando-a como a de todos os portugueses, manifestando uma valorização positiva do atleta nacional. Na realidade, o resultado e o recorde parecem assumir uma importância tal que se pode afirmar que o desporto para pessoas com deficiência se encontra enquadrado com a lógica do desporto moderno, esperando-se que o atleta incorpore o homem sem limites, algo também visível nas prospecções e expectativas geradas em torno das suas provas.

Finalmente, cabe-nos dizer que as conclusões apresentadas são fruto de uma discussão fortemente centralizada nos nossos resultados e não tanto no confronto com a literatura mais específica, dada a sua escassez. Destarte, esta reduzida produção de conhecimento na área da actividade física adaptada parece ir ao encontro da realidade social por nós estudada e discutida.

CORRESPONDÊNCIA

Maria Adília Silva

Faculdade de Desporto

Universidade do Porto

R. Dr. Plácido Costa, 91

4200-450 Porto

PORTUGAL

madilia@fcdef.up.pt 


\section{REFERÊNCIAS}

1. A.A. (1999). Dicionário de Língua Portuguesa. Porto: Porto Editora ( $8^{\mathrm{a}}$ ed.)

2. António B (1993). Olimpíadas/Paralimpíadas. Minusval Revista del Servicio Social de Minusválidos Ano XX (82): 98 100

3. Bardin L (1977). Análise de conteúdo. Lisboa: Edições 70

4. Borcila A (2000). Nationalizing the Olympics around and away from 'vulnerable' bodies of women. The NBC coverage of the 1996 Olympics and some moments after. Journal of Sport \& Social Issues 24 (2): 118-147

5. Bourdieu P (1997). Sobre a televisão seguido de A influência do jornalismo e os Jogos Olímpicos. Rio de Janeiro: Jorge Zahar Editor

6. Brittain I (2004). Perceptions of disability and their impact upon involvement in sport for people with disabilities at all levels. Journal of Sport \& Social Issues 28 (4): 429-452

7. Calvo A (2001). Desporto para Deficientes e Media Análise evolutiva do tratamento mediático dos Jogos Paralímpicos em quatro periódicos nacionais (1988/1992/1996). Dissertação de Mestrado. Porto: Faculdade de Ciências do Desporto e de Educação Física, Universidade do Porto

8. Carvalho J (1999). Preparação da Missão Paralímpica de Sydney 2000. Estoril: Associação Nacional de Desporto para a Deficiência Mental

9. Dias B (2001). Direitos humanos, cidadania e deficiência. In Dias J (ed.) Cidadania e deficiência. Évora: Associação Pós-Pólio de Portugal, 21-38

10. Erbring L, Goldenberg E (1980). Front-page news and real world cues: a new look at agenda-setting by the media. American Journal of Political Science 24 (1): 16-49

11. Federação Portuguesa de Desporto para Deficientes (1996). Desporto para deficientes a nível mundial. FPDDInformação (10): 5

12. Gaillard P (1971). O Jornalismo. Mem Martins: Publicações Europa-América

13. Gamson W, Croteau D, Hoynes W, Sasson T (1992). Media Images and the social construction of reality. Ann. Rev. Sociol. 18: 373-393

14. Garcia R (2000). Desporto para pessoas com deficiência uma perspectiva ética. In Lemos K (Ed.) Temas Actuais V. Educação Física e Esportes. Belo Horizonte: Editora Health, 83-92

15. Gervilla E (1993). Postmodernidad y educación. Valores y cultura de los jovenes. Madrid: Dykinson

16. Grawitz M (1993). Méthodes des sciences sociales. Paris: Éditions Dalloz
17. Keller C, Hallahan D, McShane E, Crowley E, Blandford B (1990). The coverage of persons with disabilities in american newspapers. The Journal of Special Education 24 (3): 271-282

18. Maas K, Hasbrook C (2001). Media promotion of the paradigm Citizen/Golfer: an analysis of Golf magazines' representations of disability, gender, and age. Sociology of Sport Journal (18): 21-36

19. Manha J (1989). Jornalismo (dito) desportivo. A especialização contra a especulação. In Direcção Geral dos Desportos (Ed.) Seminário Desporto e Comunicação Social, Desporto e Sociedade. Lisboa: Ministério da Educação, 37-44

20. Moura e Castro J (1996). O deficiente e o desporto. Revista Horizonte 74 (13): 26-30

21. Moura e Castro J, Garcia R (1998). O desporto, a performance e a estética do corpo diferente. In Marques A, Prista A, Faria Júnior A (Eds.) Educação Física: Contexto e Inovação - Actas do V Congresso de Educação Física e Ciências do Desporto dos Países de Língua Portuguesa. Maputo: FCDEF-UP, FCDEFUPM, 203-213

22. Neiva J (1997). Igualdad y Diversidad: el respecto-reconocimiento del otro. Un valor fundamental. In M. Patrício (Ed.) A escola cultural e os valores. II Congresso da Associação da Educação Pluridimensional e da Escola Cultural (AEPEC). Porto: Porto Editora, 189-207

23. Patrício M (1993). Lições de Axiologia Educacional. Lisboa: Universidade Aberta

24. Sanmartín M (1995). Valores sociales y deporte - La actividad física y el deporte como transmisores de valores sociales y personales. Madrid: Gymnos, Editorial Deportiva, S.L.

25. Schantz O, Gilbert K (2001). An Ideal Misconstructed: Newspaper Coverage of the Atlanta Paralympic Games in France and Germany. Sociology of Sport Journal 18 (1): 6994

26. Shell L, Duncan M (1999). A content analysis of CBS's coverage of the 1996 Paralympic Games. Adapted Physical Activity Quartely 16: 27-47

27. Silverman D (2000). Analysing talk and text. In Lincoln Y (Ed.) Handbook of qualitative research. California: Sage Publications, Inc, 821-834

28. Thomas N, Smith A (2003). Preoccupied with able-bodiedness? An analysis of the british media coverage of 2000 Paralympic Games. Adapted Physical Activity Quartely 20: 166-181

29. Vala J (1986). A análise de conteúdo. In Madureira Pinto J (Ed.) Metodologia das Ciências Sociais. Porto: Edições Afrontamento, 101-128. 